\title{
LA NOCIÓN DE FORMA EN LA IMAGEN: ¿QUÉ FACTORES LA GONDICIONAN?
}

\author{
THE NOTION OF FORM IN IMAGE: \\ WHAT FACTORS CONDITION IT?
}

\section{Fabián Cordero Salazar}

Ecuatoriano. Diseñador (1995) y Magíster en Proyectos de Diseño (2016) graduado de la Universidad del Azuay en Cuenca, Ecuador. Con más de veinte años de actividad profesional independiente en el mundo del diseño y la comunicación gráfica ha incursionado en las áreas del diseño editorial, diseño publicitario, packaging, diseño web y diseño de identidad corporativa. Cuenta con experiencia profesional de más de quince años en el área de la producción de impresos y tecnologías de preprensa en la industria local. Actualmente es profesor investigador de la Facultad de Diseño, Arquitectura y Arte de la Universidad del Azuay, miembro del equipo académico-administrativo de la Escuela de Diseño Gráfico y Coordinador de Comunicación de esta misma Facultad. Ha participado además en proyectos de investigación, cuyas líneas se orientan hacia el estudio de las relaciones del diseño de comunicación gráfica, el uso del espacio público y el diseño experiencial.

efcordero@uazuay.edu.ec

Fecha de recepción: 5 de abril, 2016 / Aceptación: 12 de abril, 2017. 


\section{Resumen}

La imagen, como producto de diseño, y la noción de su forma están condicionadas por varios factores. Ya sea como productores o receptores de una imagen, comprender cómo y por qué le asignamos determinada forma implica entender cómo estos factores interactúan. En una imagen, la forma es influida por el medio que la posibilita, por el contexto en el que se crea y desenvuelve y por los interactores que la producen, la perciben y la valoran a partir de sus experiencias y de los paradigmas desde los cuales actúan. La introducción de diferentes variables implica que se produzcan nociones diferentes, pero no excluyentes, de lo que entendemos como forma en una imagen.

Palabras clave: contexto, cognición, interactores, modos de la imagen, modelos interpuestos, percepción.

\section{Abstract}

Image as a product of design and the notion of its form is conditioned by many factors. Whether as producers or recipients of it, understanding how and why a determined shape is assigned implies an understanding of how those factors interact with each other. In an image, form is influenced by the medium which makes it possible, by the context in which it is created and developed, as well as by the interactors that produce it, perceive it, and value it from their experiences and from the paradigms under which they act. The introduction of different variables implies that different, yet not excluding, notions of what we understand as form in an image are produced.

Keywords: context, cognition, interactors, image mode, interposed models, perception. 


\section{Introducción}

En el texto que se desarrolla a continuación nos adentramos brevemente en el análisis de los aspectos que influencian y condicionan las nociones de forma en una imagen. Nos referiremos a la imagen que surge como producto de la creación del ser humano, esa imagen que es ideada, creada y construida, en suma, la imagen que es producto de un acto de diseño y que de esa manera se convierte en el objeto de estudio del diseño gráfico. El objetivo es efectuar un análisis desde diferentes enfoques, que nos proporcionarán también diferentes nociones de lo que podemos entender como forma en una imagen. La hipótesis de la que partimos es que estudiar la forma en la imagen desde un solo punto de vista resulta simple y reduccionista, y que más bien hay que abordar la forma desde diferentes posicionamientos y variables para encontrar en ese recorrido las relaciones existentes entre los enfoques. Solo de esa forma podemos entender mejor la imagen y, por lo tanto, podemos utilizarla de forma más adecuada como sustancia del diseño gráfico.

Partiremos de una premisa fundamental: el convencimiento de que no puede existir ni una sola visión ni una sola versión de la realidad, por lo que las diferentes consideraciones de análisis con las que abordaremos el tema resultan complementarias y necesarias para lograr una aproximación más sólida a esas nociones de forma en la imagen. Analizaremos la influencia del soporte, el medio que la sostiene y posibilita y las mutaciones o cambios de modo que ha tenido a través del tiempo. Nos ocuparemos también de la influencia del contexto en la producción de las formas de la imagen, de esta manera intentaremos observar la influencia de la cultura, de la tecnología y de los paradigmas de un imaginario social determinado en su producción; además, analizaremos cómo el contexto físico-espacial e histórico-evolutivo resultan importantes en el momento de hablar de las nociones de forma que podemos tener de las imágenes. Finalmente, nos referiremos al papel del sujeto productor y receptor como interactor con la imagen e indagaremos sobre los procesos perceptivos del ser humano, el desarrollo cognitivo y los modelos interpuestos en la creación y recepción de la imagen.

\section{El medio de soporte y la forma en la imagen}

Los distintos momentos históricos del ser humano han posibilitado diferentes modos de producción y soporte de las imágenes, cambios en los paquetes tecnológicos que han influenciado decisivamente en la forma que dichas imágenes pueden adquirir, pero no solamente refiriéndonos al aspecto físico, sino también la forma y la función simbólica de la imagen en cada contexto, es decir, la forma en que actúa la imagen. Tomamos aquí como referencia a las tres principales mutaciones de la imagen a las que José Luis Brea se refiere: la imagen-materia, la imagen fílmica y la imagen electrónica (Brea, 2007).

En el primer modo de la imagen, la imagen-materia, está asociada unitariamente a su soporte; la tecnología que la posibilita pertenece a medios meramente materiales y tangibles; es más, la imagen-materia conforma una sola entidad con el medio físico que la sostiene, depende de esa materialidad. Esa característica determina que la forma dependa de las propiedades físicas de esos materiales y de las posibilidades tecnológicas reales para ser transformada. En el aspecto simbólico, la imagen-materia es tangible y perdurable, por lo que actúa como una memoria del mundo, como un símbolo de eternidad, pues posee la capacidad de hacernos trascender. Desde su individualidad como pieza única e irrepetible actúa también como símbolo de afirmación identitaria.

La segunda mutación de la imagen de la que nos habla Brea (2007), la imagen fílmica, ya no constituye una imagen firmemente asociada a su soporte como en el caso de la primera, sino que es una imagen que más bien flota sobre una superficie inmaterial; las formas ya no están ancladas a la 
materialidad ni dependen de la técnica, sino más bien de los condicionamientos de carácter óptico y temporal. Desde el aspecto simbólico, estamos ante una imagen dinámica que sucede y acontece, se liga al tiempo y por ello es efímera, pasajera, deja de ser una promesa de lo perdurable como la imagen-materia; es una imagen con capacidad narrativa fácilmente articulable con el devenir histórico social.

La tercera mutación de la imagen, la imagen electrónica, pierde ya totalmente el anclaje a un soporte material. Lo que la posibilita y da forma no es la combinación del recurso material con las capacidades tecnológicas o la capacidad de la luz como fenómeno óptico; la materia prima de esta nueva versión de imagen es la información, paquetes de bites que, según su combinación, nos representan una u otra cosa, "la materia ya no es un conjunto determinado de materiales, sino un sistema de lenguajes, de conocimientos y de tecnologías. El problema que se plantea con estos materiales es que ya no es tan fácil verlos, conocerlos y convertirlos, como se ha hecho siempre, en estímulos para la creatividad" (Manzini, 1992, p.121).

La imagen electrónica de hoy en día, además de no estar anclada a un soporte, adquiere una particularidad interactiva muy superior a la imagen-materia. Esta última es netamente pasiva, sus capacidades no van más allá de lo que nosotros como observadores le damos, aunque ella se nos muestre y esté en capacidad de inquietarnos 0 incluso de interrogarnos, el sujeto como intérprete es quien la llena de significados. Por el contrario, de la imagen electrónica e interactiva de hoy en día nosotros siempre esperaremos algo más, esperamos un modo de comportamiento, que está en capacidad de interactuar con nosotros. Si bien depende de nuestras percepciones, depende también de ella misma, se convierte en una imagen casi sujeto en la que, como plantea Manzini (1992), "su capacidad de producir significados se configura como la articulación de un coloquio" (p.156). De este modo, continúa Manzini, al hablar de los objetos casi sujetos (de entre los cuales nos atreveríamos a afirmar que la imagen, en esta civilización de la imagen, es el objeto predilecto):

La interactividad es algo que se da en el tiempo (...) para la cultura del diseño, cuyo rol central ha sido siempre el de dar calidad a formas en el espacio, ocuparse de la interactividad significa, pues, aventurarse en un territorio totalmente nuevo, cuyas referencias culturales provienen más bien del cine, del teatro, de la música; es decir de actividades en las que la calidad se produce precisamente organizando secuencias de acontecimientos (p.157).

Y he ahí entonces que esta última mutación en los soportes de la imagen nos revela incluso una nueva dimensión en la que ocuparnos en el momento de pensar en la noción de la forma, una cuarta dimensión, en este caso temporal, más allá de las dimensiones espaciales.

Simbólicamente, como nos dice Brea (2007), la imagen electrónica constituye una imagen desprendida e independiente, una imagen fantasmal y puramente psíquica, adquiere un potencial como catalizadora de las figuras del deseo y, por tanto, es fácilmente articulable con este mundo actual del espectáculo que producen las nuevas formas de mercancía. Es, además, por no definirse en un soporte, una imagen desprendida de ubicación, lo que la vuelve aún más fantasmal e infinitamente repetible y abundante.

Pero relacionar los diferentes paquetes tecnológicos que posibilitan la creación y soporte de las imágenes a través del tiempo con la función simbólica que cada uno implica, pretende conducirnos a estas preguntas: ¿en qué medida los medios que soportan la imagen condicionan nuestros modos de pensamiento? Y yendo más allá, ¿cómo esos nuevos modos de pensamiento determinan la ideación, creación y asimilación de nuevas formas?

Como todo lo creado a través del diseño, también la imagen es expresión y reflejo de los aspectos de la cosmología del ser humano; es un instrumento, cada vez más importante de encuen- 
tro entre las personas porque, como lo anota Augé (2000), cuando los objetos circulan, se exhiben, se intercambian y se utilizan, se convierten en un medio de relación entre los seres humanos y es entonces cuando adquieren connotaciones simbólicas. La imagen como el objeto producto de la creación en el diseño gráfico también lo hace. Las imágenes constituyen de ese modo un punto de encuentro entre los interlocutores, un vínculo que establece relaciones entre los actores de una sociedad, vínculo que, a la vez, en su creación, se nutre de estos actores y de las relaciones de estos con el contexto en el que se desenvuelven. Trabajar la imagen implica entonces considerar un mundo externo, un contexto en el que se tejen una serie de relaciones.

\section{El contexto y la forma en la imagen}

a) La influencia de los paradigmas sociales

La historia del ser humano está ligada a la producción de imágenes. Ya hace más de 20000 años, inscripciones sobre los muros de las cavernas iniciaron el camino de la creación y utilización de imágenes por parte del ser humano (figura 1) porque este buscó representar su realidad, preservar y dejar registro de los hechos de una manera que trasciendan. También utilizó la imagen como forma de aproximarse fuera de los límites de su entorno físico al usarla, por ejemplo, en rituales mágicos. Hablamos así de un primer tipo de superficie de inscripción como aparato tecnológico y como soporte de la cultura que el ser humano utilizó luego de la comunicación oral y que tomó por primera vez y para siempre, a la imagen como régimen ${ }^{1}$ discursivo.

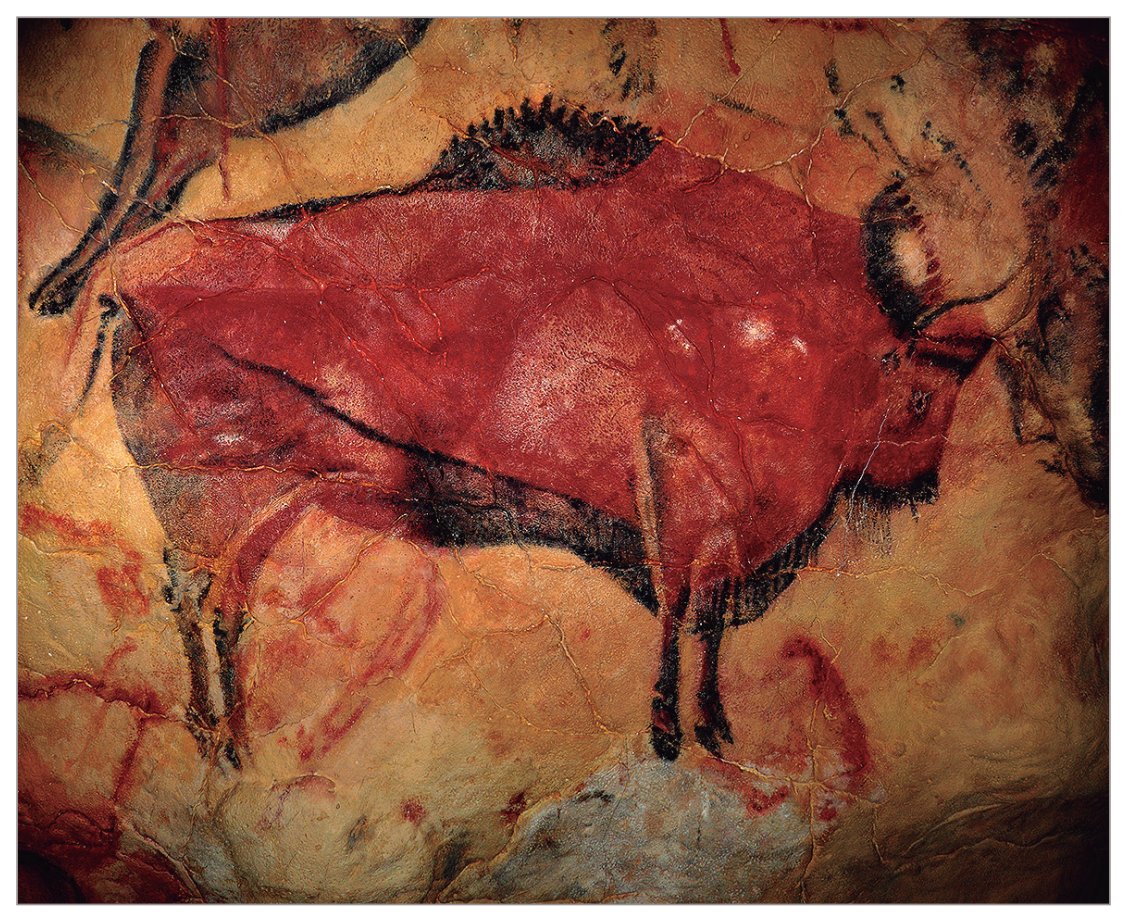

Figura 1. Pintura rupestre encontrada en las cuevas de Altamira, Cantabria, España (Museo Nacional y Centro de Investigación de Altamira, 2008). 
Al pasar el tiempo, el ser humano agrupado en sociedades adquiere la costumbre de marcar sus pertenencias y su propio cuerpo, práctica relacionada con su necesidad de identificarse e identificar lo suyo, de reconocerse a sí mismo y de reconocerse ante los demás; la imagen y las formas que ella adquiere actúan como un reflejo de sus maneras de relacionarse y como una expresión de sus creencias, en suma, se comportan como un recurso identitario (figura 2).

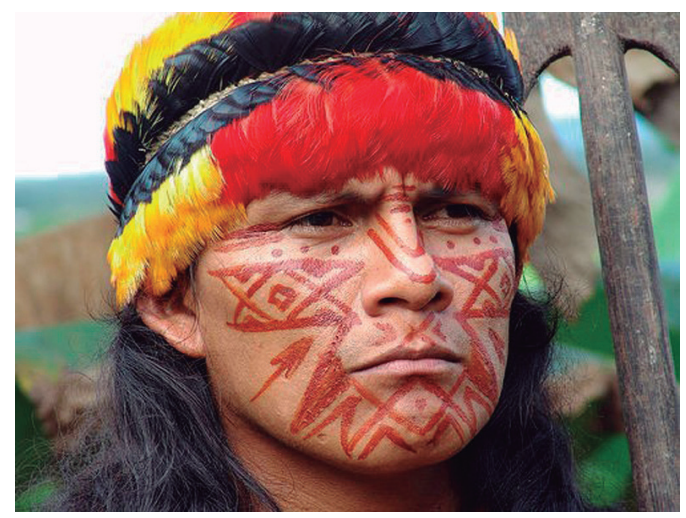

Figura 2. Gráfica corporal, grupo étnico Shuar (Enríquez, 2013).

Esta imagen como forma de expresión y comunicación evolucionó hacia la escritura ideográfica y luego a la escritura fonética, cuando el ser humano descubrió que sus pensamientos podían no solamente traducirse en imágenes 0 en la palabra hablada, sino que podían existir también una manera en que su historia quedara plasmada como verbo y a la vez como imagen. Así, la primera forma de escritura ideográfica que utilizó imágenes para representar ideas evolucionó hacia la escritura fonética, cuando los signos se asociaron con sonidos. Fueron los fenicios, tenaces comerciantes del antiguo Mediterráneo, quienes por condicionamientos de su actividad principal y su forma de vida y cultura, el comercio -o valdría decir por el imaginario colectivo construido en su sociedad- debieron adaptar la escritura ideográfica que conocían a sus necesidades particulares, y la transformaron en una escritura de tipo fonético, en la que signos debieron adaptar su forma para poder ser entendidos más fácilmente por más personas, para que resultara más funcional a sus propósitos (figura 3).

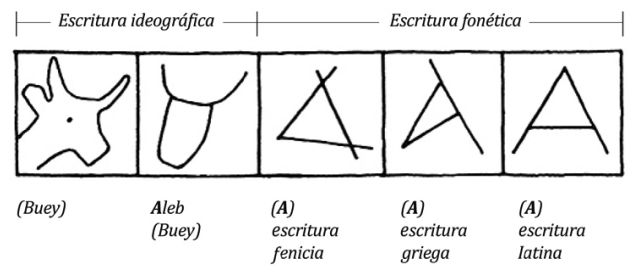

Figura 3. Ejemplo de la evolución de la escritura, letra latina A (Autoría propia, 2016).

A través de este ejemplo podemos ver cómo las condiciones de un imaginario social impusieron un nuevo modelo que significó también una nueva forma de expresión (la escritura fonética) y, por tanto, nuevas formas en la imagen, adaptadas a ese imaginario social.

Antes los egipcios, luego griegos y romanos se sirvieron de la imagen para representar su cotidianidad, la pesca, la caza, las guerras y celebraciones, luchas y danzas, en fin, la vida misma fue plasmada de diversas maneras, a través de diferentes técnicas y con el uso de diferentes concepciones en las formas.

Más adelante, la riqueza de las artes plásticas en el Renacimiento nos revela la evolución de la sociedad hacia el uso de nuevas formas en la imagen. El uso de la perspectiva (figura 4) en esta época también es una muestra muy clara de cómo nuevas formas de expresión se van creando en función de los cambios en el imaginario social: en el Renacimiento, el ser humano como centro del universo necesitó plasmar sus imágenes de modo que estuviera fuera, de modo que lo represente como el que domina el punto de vista. Se crea un sistema de representación que obviamente incide en la forma de la imagen, pero que no emerge casualmente, sino parte de un paradigma de la época: una visión antropocéntrica. 


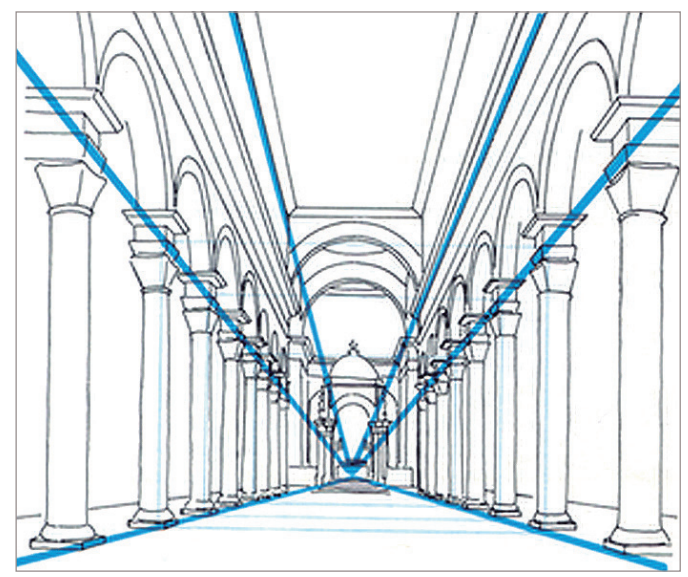

Figura 4. Perspectiva (Aula de Historia, 2013).

Yendo más adelante en el tiempo, los avances de la civilización en la era industrial provocan también cambios en las formas de expresión. El sistema Monge (figura 5) de representación, por ejemplo, surge como respuesta a las particularidades comunicativas de una época en la que la reproducción en serie es el concepto. Esto nos muestra una vez más cómo la gestación de una sincronía cultural de una época impulsa a la técnica que a su vez termina por definir la forma de la imagen.

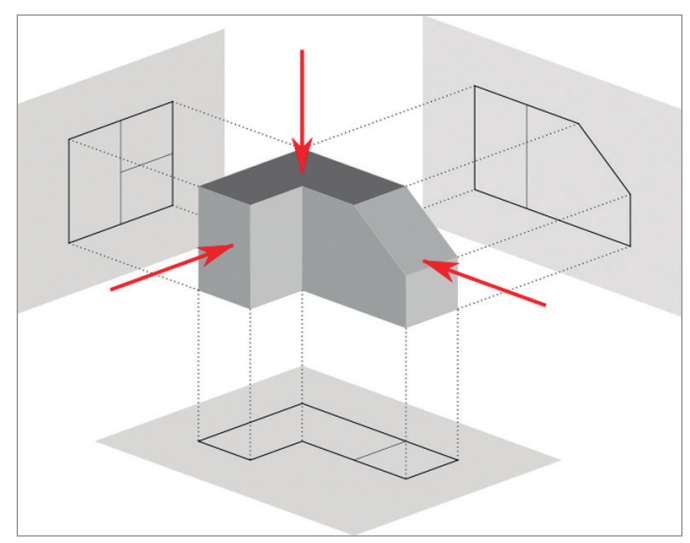

Figura 5. Sistema de representación Monge. Diédrico (IDIS, 2016).
No podemos dejar de mencionar a la fotografía, que trajo consigo una nueva forma de representar la realidad y se abrió paso en la historia del arte hasta llegar a museos y galerías. El ojo del artista da a la fotografía un estatus de creación, así pasa a ser, algo más que un mero fenómeno físico-mecánico, algo más que la simple captura de la realidad.

Los finales del siglo XX y lo que va del XXI nos traen consigo cambios tan profundos y radicales que también se reflejan en la forma que adquieren las imágenes, principalmente con el uso de los medios digitales (figura 6), las tecnologías de la información y comunicación y la Internet.

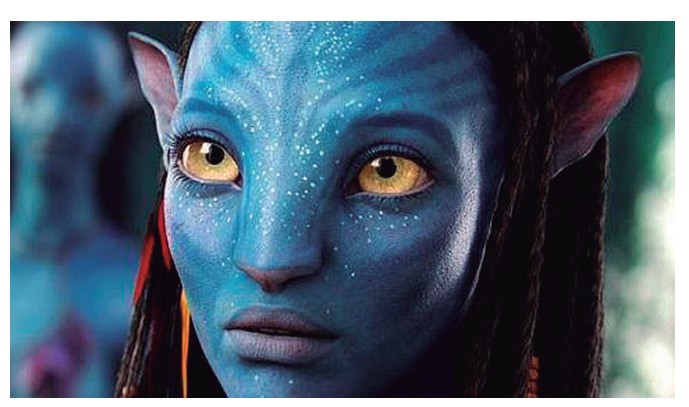

Figura 6. Imagen producida digitalmente para la película Avatar (Adams, 2014).

La relación forma-técnica es parte de una concepción del imaginario social de cada momento histórico, pero el paradigma cultural de cada época no solo incide en la forma a través de la tecnología que se usa para plasmarla, sino que incide también en los conceptos con que esa forma se aborda y se concibe, es por eso que, por ejemplo, la perspectiva como instrumento tecnológico condiciona la forma de las imágenes, pero no desde la aplicación de una técnica únicamente (puntos de fuga), sino principalmente desde el concepto en el que emerge (el observador fuera).

Una serie de regímenes, que al pasar del tiempo han alterado nuestra forma de construir el mundo, han modificado nuestras sensaciones y han impulsado a la técnica para proveer los recursos necesarios que transforman los conceptos en formas. De ese modo, la forma es condicionada mecánica- 
mente por la técnica, pero también por la pulsión de las ideas de un imaginario social en una determinada época.

El debate actual del diseño se mueve alrededor de la pregunta de cómo debe insertarse en la dinámica cultural contemporánea, pues hoy, lejos de hablar del diseño como solucionador de problemas 0 de una objetividad en los modelos de representación, hablamos de variabilidad y de construcción de sentido con el contexto como referente. En efecto, en el contexto se produce una dinámica vincular porque todas las variables de la cultura se interconectan entre sí, y en este, el sujeto no actúa como un ente pasivo, sino más bien supone un devenir en estas interacciones $y$, seguramente, tal como en los diferentes momentos históricos ha ocurrido, ese imaginario social que se va gestando en la contemporaneidad influirá también en la producción de las formas.

\section{b) La influencia del contexto espacial}

El contexto en un primer nivel supone el aspecto cultural, económico y tecnológico; en otro nivel, supone la parte social. Los aspectos sociales inciden en la forma de relacionarnos con otras personas, pero, como hemos visto, inciden también en la forma en que nos relacionamos con los objetos, en este caso, con las imágenes.

Pero las imágenes como los demás objetos conviven físicamente con otras imágenes y con otros objetos en una relación permanente, pues no están aisladas en el espacio, ese contexto influye en ellas. El contexto, en esencia, lo configura todo aqueIlo que no consiste en el objeto de estudio, pero que se relaciona con este de alguna manera; no es algo inmóvil, al contrario, cambia constantemente y conforme redefine sus límites también redefine los de la imagen, "Lo ambientes no constituyen envolturas pasivas, sino más bien procesos activos invisibles. Las reglas fundamentales, la estructura penetrante y los patrones generales de los ambientes eluden la percepción fácil" (McLuhan, 1967, p.68).

También la semiología resalta la influencia del contexto. El valor de un signo para esta disciplina resulta de la presencia simultánea de otros, los signos no tienen esencia por sí mismos, sino que están más bien definidos por una red de relaciones, no funcionan por su valor intrínseco, sino por su posición relativa, es decir, nada tiene significado por sí mismo. Yendo más allá, en un nivel más cercano al objeto (la imagen), el contexto espacial está constituido por el conjunto de características que definen las piezas diseñadas con un fin común, a lo que generalmente los diseñadores solemos llamar el sistema gráfico; y por último, en un nivel interno, el contexto lo conforman también las reglas que definen las relaciones entre los elementos compositivos de la pieza gráfica, como el color, la textura, la escala, etc.

\section{c) La influencia del contexto histórico-evolutivo}

Hemos hablado de la importancia de los modelos de un imaginario social en la determinación de la forma en la imagen y de cómo esto se articula muchas veces a través de la técnica y la tecnología imperante en el momento (que en general surge como fruto de esos mismos paradigmas), y hemos hablado incluso de procesos de mutación en la imagen. Ahora debemos mencionar un componente evolutivo que influye en la imagen, pues a nuestro criterio existe también evolución en el desarrollo de la forma en la imagen, con todas las características que esta palabra implica.

Ya mencionamos que el mundo está constituido de partes y de una dinámica vincular en donde se producen conexiones e interacciones entre estas partes,

Dos razones sustentan estas conexiones parciales dentro de las unidades operacionales del diseño: los componentes guardan la memoria del mundo al que pertenecían y desde la que han sido tomados; por lo tanto, traen consigo expresiones y contenidos, formas y sustancia de vidas pasadas, de otras unidades operacionales. Y luego, una vez que está ya construido el objeto que se quería, esos mismos elementos están listos 
para marcharse a ser parte de otras unidades operacionales. Hay aquí una inquietud que no les deja permanecer quietos y que los obliga a desplazarse constantemente (Rojas, 2012, párr. 5).

Toda imagen anuncia la que viene, todo objeto encarna la posibilidad de un objeto nuevo, todo espacio supone la apertura de otras espacialidades; y en el caso de la moda, siempre proviene de una anterior que la contenía de algún modo. Esta prefiguración se convierte en una característica general de la sociedad y de la cultura, contiene dentro de sí aquellos aspectos que pueden desembocar en la creación de una sociedad alternativa u otra cultura (Rojas, 2014). Como lo entendemos, ese camino preconfigurado en la creación de las formas supone una característica evolutiva que es la misma que está presente en la evolución cultural y social.

Las imágenes y los objetos creados, como todo elemento sujeto a una evolución, deben adaptarse al medio en el que están insertos para poder permanecer a través del tiempo. Según postula Wagensberg (2004), "todo lo que existe es el resultado de una selección" (p.60) y en ese sentido una forma permanece y evoluciona gracias a una propiedad importante: su función. A diferencia de la selección fundamental y natural que se encuentran con la función cuando esta surge por el azar, la selección cultural sale en la búsqueda de esa función; la imagen evoluciona por ser funcional y también por ser bella. Como el diseño es arte y ciencia (como ciencia está en la capacidad de conocer, de organizar conocimientos) y como arte está en la capacidad de conmover con lo bello. En esta característica ocurre el proceso de selección cultural operado por el ser humano (diseñador) que imprime a los objetos e imágenes caracteres adquiridos (Lamarck) más que cambios azarosos (Darwin); el principio que rige la selección es la necesidad y el deseo de eficiencia, utilidad y belleza como factores requeridos que condicionan su evolución.

En esencia, la imagen y su forma evolucio- nan porque sus cambios dependen de las características tecnológicas o de las condiciones de un imaginario social de la época, siempre transmiten "genes" (memes si hablamos de aspectos culturales) por la selección cultural operada por el ser humano fruto de una necesidad, por la funcionalidad comunicativa, la eficiencia o la belleza.

\section{Los interactores y la forma en la imagen}

a) Los modelos interpuestos

A nuestro juicio, una premisa importante al hablar de la imagen es la mirada o el posicionamiento desde el cual se produce y evalúa una imagen. Este posicionamiento incide en la representación que de esta se hace a partir de la imagen; introducir diferentes variables puede dar lugar a que la representación de un mismo elemento cambie, pues con la variable introducida cambian las consideraciones desde las cuales se valora y entiende dicho elemento. Entre un referente y su representación se interpone un modelo, así la representación del cuerpo humano no es la misma si se interpone un modelo cientificista moderno -que grafica al cuerpo humano como un todo conformado por sistemas relacionados pero independientes- 0 un modelo holístico -que cartografía al cuerpo humano mediante los meridianos energéticos y el recorrido e interrelación de estas energías, el cuerpo como una red energética integrada donde las partes no pueden entenderse aisladamente- (figuras 7 y 8 ).

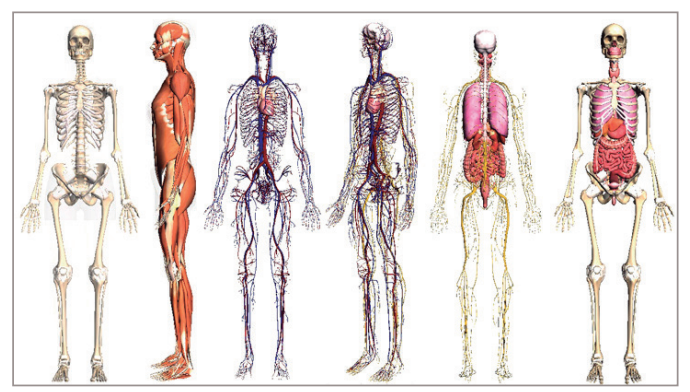

Figura 7. Modelo cientificista moderno (Arzabal, 2016). 


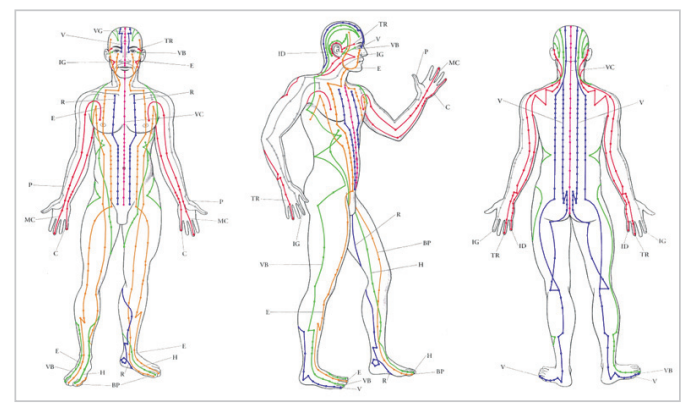

Figura 8. Modelo holístico (Instituto Qigong, 2016).

Desde esta perspectiva, la forma como producto del diseño no puede ser considerada solamente como el resultado de procesos que aprecian por su utilidad, funcionalidad o características estéticas, sino también como el resultado de procesos de producción de significados influenciados por los modelos desde los que se genera. La forma está influida por el medio en que se despliega, por el contexto y por los interactores parte de ese contexto, es decir, de sus productores, que son quienes la perciben y la valoran en función de su propia experiencia y de los paradigmas desde los cuales actúan.

Como manera de ejemplificar esta idea, podemos mencionar las características de las formas en el arte islámico (figura 9) donde los motivos, temas e iconografía son geométricos y arabescos. Esta representación se explica si entendemos el papel de la religión musulmana en el desarrollo del arte islámico. La caligrafía y motivos arabescos y geométricos poseen connotaciones sagradas para el islam: los suras del Corán se consideran palabras divinas, la caligrafía se concibe como un arte sagrado y las representaciones de seres vivos no son permitidas en los libros ni en lugares religiosos. Observamos, entonces, una relación directa entre los modelos mentales (los religiosos) y la producción de las formas.

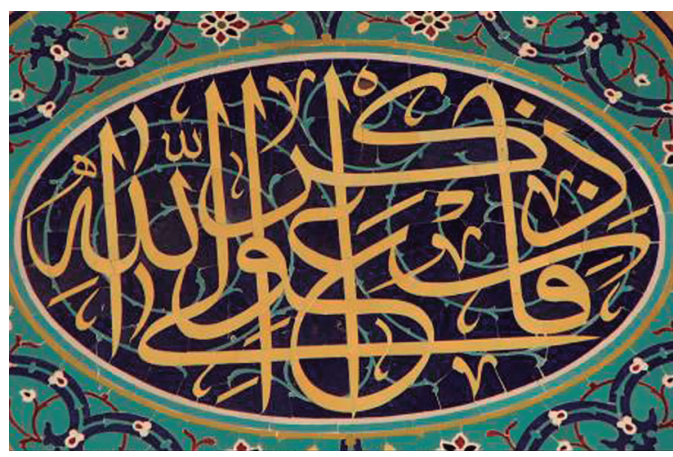

Figura 9. Mosaico islámico (Fundación Cultural Oriente, 2016).

b) Forma, expresión y experiencia

Forma y expresión están estrechamente unidos. "La forma es lo que define a una cosa como tal, la manera en que el material construye la cosa. Expresión es lo que despliega una cosa como tal, lo que muestra la cosa" (Hallnas, citado por Rojas, 2014, p.5). La expresión de la forma produce la experiencia, pero la expresión que podemos dar a una forma diseñada no se vincula solamente con la experiencia de uso que se dará a esa forma.

Experimentamos lo que se nos presenta, pero en este sentido debemos entender que, si bien una imagen diseñada con una forma determinada nos expresa algo, lo que nosotros entendemos de ella no está ligado simplemente a lo que esta nos dice, sino que se liga con lo que adicionamos como observadores, pues interactuamos con la imagen. Las imágenes que vemos no solamente se nos muestran, se vuelven otra imagen dentro de nuestros cerebros, una nueva imagen influenciada por nuestra particular forma de percibir las cosas y por el contexto. Captamos una imagen con los contenidos que nosotros adicionamos, recomponemos la imagen con elementos que provienen de nosotros mismos. "Los espectadores ven, sienten y comprenden algo en la medida en que componen su propio poema" (Ranciére, 2013, p.20).

"El carácter decisorio entre la intencionalidad del emisor y la decodificación del receptor no es unívoca" (Sexe, 2008, p.77). Peirce, el padre de 
la semiótica, argumentó que los intérpretes proporcionan parte de los significados de los signos, que un signo es algo que está para alguien por algo en algún aspecto 0 capacidad. 0 como diría Bruno Munari (2016): "Cada cual ve lo que sabe" (p.20). Para Saussure, la relación del significado con el significante es arbitraria, no hay correspondencia entre un significado y un significante o viceversa. No hay nada de una casa en el signo casa, ni ninguna propiedad de una camisa en el signo camisa y así siempre.

Así que diseñamos no solamente formas, no solamente significantes, diseñamos expresión y de la mano de la expresión diseñamos experiencias en quienes interactúan con la forma, experiencias vividas y creadas también desde dentro de estos interactores como respuesta a lo que proponemos; diseñamos, por tanto, en conjunto con el observador, más que formas, experiencias, significados y maneras de ver y usar las imágenes.

Una tiza será para un pintor una mancha, para un físico una estructura molecular, para un químico una combinación de elementos, para un maestro una herramienta. Es cada una de esas cosas, y sin esas referencias o destinos no es nada, es el ser antes de la captación, es la materia, es decir, lo dado, calificado, en suma, por su falta de captación. El modo de su existencia es diferente según sea la acción transitiva cuyo sujeto es el Yo (Giordano, Wainhaus, Pescio, Pereyra y Frigerio, 2003, p.65).

\section{c) Los procesos cognitivos}

Para la psicología cognitiva, la percepción se concibe como una actividad del pensamiento: ver y pensar suponen prácticamente los mismos procesos. La teoría de la Gestalt, en cambio, diferencia la percepción visual del pensamiento porque, argumenta, existen formas impensables que pueden verse y formas que se pueden pensar, pero no ver; y porque percepción visual y pensamiento se rigen por leyes diferentes. Las investigaciones actuales no suponen que estas corrientes son contradictorias y propone una integración de aportes: el sujeto va construyendo infinidad de redes neuronales en su cerebro, que responden a los estímulos más frecuentes, conforma así caminos conocidos que marcan hábitos y tendencias. La imagen de esta manera está vinculada estrechamente con los mecanismos de percepción y la memoria de la experiencia previa. Ciertamente, Jung afirmó, si recordamos, que todo aquello que no queda en la conciencia, lo que está en el inconsciente, opera como una base de datos que constituye la base de la conciencia creativa del ser humano.

A grandes rasgos, podemos darnos cuenta de la complejidad del estudio de los procesos cognitivos del cerebro humano, tanto que existen varias corrientes y tendencias de estudio en este campo, pero todas coinciden en afirmar que, aunque biológicamente estamos configurados de forma similar, poseemos una particular manera de entender e interpretar el mundo y sus estímulos.

\section{Sin intención de llegar a conclusiones}

En este recorrido breve por los factores que pueden condicionar nuestra noción de forma en una imagen nos ratifica que no existe una sola forma de abordar el tema, por lo que es difícil establecer conclusiones definitivas, pero podemos sacar ciertas conclusiones porque las diferentes visiones no resultan excluyentes. En tal sentido, hemos aprendido que la intencionalidad o la mirada con la que abordamos el tema, los elementos y factores que ponemos en juego en ese proceso, encaminan las acciones y los resultados. En este aspecto, hablar de nociones de forma en la imagen necesariamente significa tomar un punto de vista y saber que cualquiera que este sea no es el único que existe.

La imagen y sus formas no nacen de una realidad estática y neutra, sino de quienes la producen y la consumen, por eso se convierten en un espacio de encuentro de las personas con su entorno. Esto da lugar a que no exista una sola versión de la realidad: el mundo es lo que cada uno percibimos 
de él, cada uno de nosotros somos lo que Sagan dijo alguna vez, el universo que se contempla a sí mismo. En esencia:

Las condiciones de producción y de reconocimiento son condiciones de producción de sentido, son condiciones de producción y reco- nocimiento de subjetividades. Estas subjetividades están constituidas por las características subjetivas de los emisores y de los receptores, por las condiciones culturales en las que están inmersos y por las condiciones materiales y tecnológicas objetivas en las que esos discursos son producidos (Sexe, 2008, p.78).

\section{Influencias en las nociones de forma en la imagen}

Figura 10. Factores que condicionan la noción de forma en la imagen (Autoría propia, 2016).

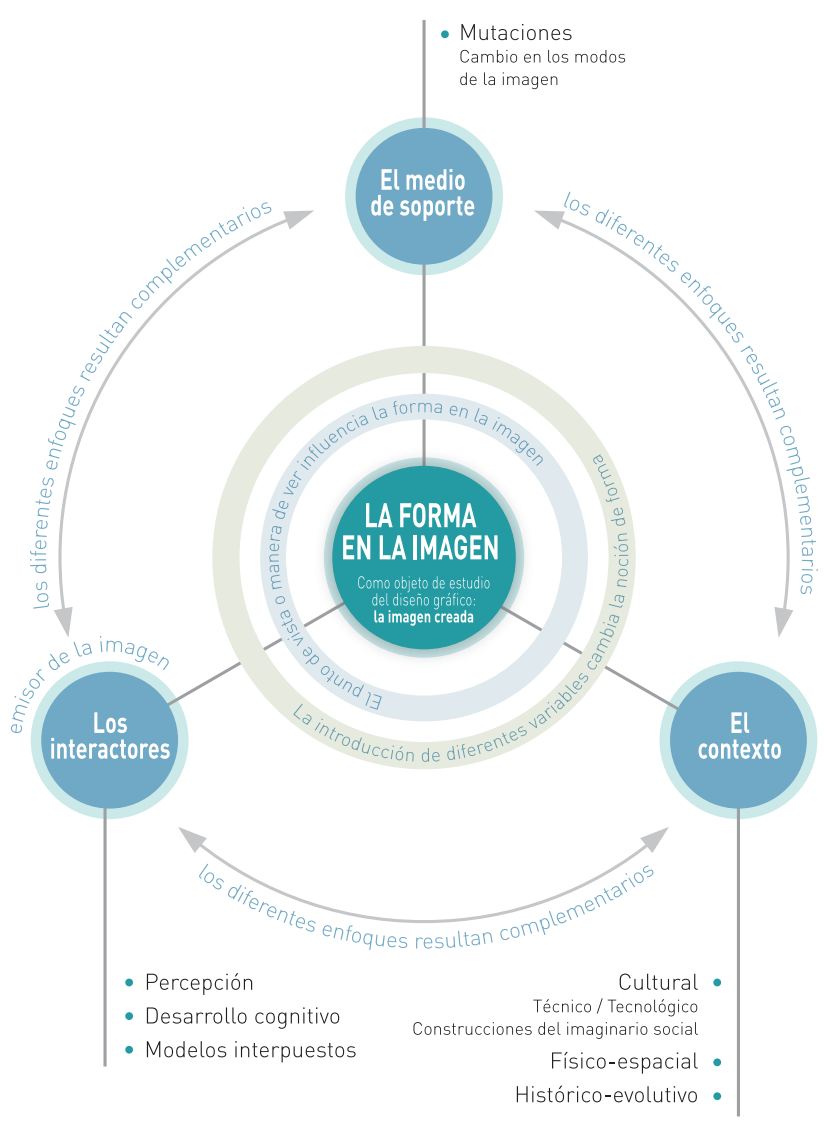

\section{NOTAS}

1 "Vamos a llamar régimen al modo en que se produce y regula la sensibilidad en una sociedad dada en un momento determinado de su existencia. El régimen estético es, por tanto, el régimen de la sensibilidad" (Rojas, 2014, p.9). 


\section{Referencias bibliográficas}

Augé, M. (2000). El diseño y el antropólogo. Experimenta No. 32, Ed. Experimenta, Barcelona, España. (pp. 90-94)

Brea, J.L. (2007). Mutaciones de la cultura en la era de la distribución de la imagen. Conferencia apertura LIPAC. Centro Cultural Rojas. Buenos Aires, Argentina: Universidad de Buenos Aires.

Manzini, E. (1992). Artefactos. Hacia una nueva ecología del ambiente artificial. Madrid, España: Celeste Ediciones.

Mcluhan, M. (1967). El medio es el mensaje. Nueva York, Estados Unidos: Bantam Books.

Munari, B. (2016). Diseño y comunicación visual. Contribución a una metodología didáctica. Barcelona, España: Editorial Gustavo Gili. Segunda Edición.

Giordano, H., Pescio, S. Pereyra, C., y Frigerio, M.C. (2003). Cinco notas sobre Heurística del diseño. Buenos Aires: FADU/Cuadernos de Cátedra.. (2005). La imagen en los procesos inventivos. En: Colección Cuadernos de Cátedra, Cinco notas sobre heurística del diseño (pp. 57-73). Buenos Aires, Argentina: Ediciones de la Facultad de Arquitectura, Diseño y Urbanismo de la Universidad de Buenos Aires.

Ranciére, J. (2013). El espectador emancipado. Buenos Aires, Argentina: Manantial.

Rojas, C. (2012). Estética del diseño 6. Conexiones parciales. Estéticas Caníbales. Recuperado de: http://esteticascanibales.blogspot.com/2012_04_01_archive.html

Rojas, C. (2014). Estética del Diseño. Cuenca, Ecuador.

Sexe, N. (2008). Diseño.com. Buenos Aires, Argentina: Paidós.

Wagensberg, J. (2004). La rebelión de las formas o de cómo perseverar cuando la incertidumbre aprieta. Barcelona, España: Tusquets Editores.

\section{Figuras}

Figura 1. Museo Nacional y Centro de Investigación de Altamira. (2008). Reproducción de un bisonte de la cueva de Altamira. Wikimedia Commons. Recuperado de: https://commons. wikimedia.org/wiki/File:AltamiraBison.jpg?uselang=es

Figura 2. Enríquez, P. (2013). Gráfica corporal, grupo étnico Shuar. Etnias del Ecuador. Recuperado de: http://pamenriquez.blogspot.com/2013/04/shuar.html

Figura 3. Cordero, F. (2016). Ejemplo de la evolución de la escritura, letra latina A.

Figura 4. Aula de Historia. (2013). La Pintura. Recuperado de: http://auladehistoriamccb.blogspot. com/2013/12/la-pintura.html

Figura 5. IDIS. (2016). Monge y el sistema diédrico. Recuperado de: http://proyectoidis.org/monge-y-el-sistema-diedricol

Figura 6. Adams. S. (2014). Daily Reads: Why no one remembers Avatar. Indie Wire. Recuperado de: http://www.indiewire.com/2014/12/daily-reads-why-no-one-remembers-avatar-thebest-blu-rays-and-dvds-of-2014-and-more-125208/

Figura 7. Arzabal. M. (2016). ¿Cuáles son los sistemas y aparatos del cuerpo humano?. Vix. Recuperado de: https://www.vix.com/es/btg/curiosidades/58303/cuales-son-los-sistemas-y-aparatos-del-cuerpo-humano

Figura 8. Instituto Qigong (2016). Red de meridianos energéticos. Recuperado de: http://webote- 
ca.net/qigong/index.php?option=com_content\&view=article\&id=5\&ltemid =7

Figura 9. Fundación Cultural Oriente (2016). Arte islámico. Islamoriente. Recuperado de: http://fotografia.islamoriente.com/es/content/arte-isl\%C3\%A1mico-\%E2\%80\%93-azulejos-y-mosaicos-isl\%C3\%A1micos-kashi-kari-realizados-en-paredes-techos-5

Figura 10. Cordero, F. (2016). Factores que condicionan la noción de forma en la imagen. 